\title{
A Short Course in Advanced Medical Teaching for Talented Hanoi Medical University Graduates
}

\author{
Owen F.Dent ${ }^{1}$, Kerry J. Goulston ${ }^{1}$, R. Kim Oates ${ }^{1}$,Van Duong Dang ${ }^{2}$, Duc Hinh Nguyen ${ }^{2}$
}

\begin{abstract}
The Australian Vietnam Medical Foundation of the University of Sydney, in collaboration with Hanoi Medical University (HMU), conducted an Advanced Course in Medical Teaching for talented recent graduates who are expected to become leaders in clinical and academic medicine in Vietnam. The intention was to deliver a part-time course taught in English which would expand their medical horizons, increase their clinical skills and help them modernize their teaching within the HMU curriculum, particularly in specifying undergraduate learning objectives and developing clinical assessment. We report on the aims, content and conduct of the first instalment of the course in Hanoi in 2010-2011.
\end{abstract}

\section{Introduction}

In 2001 the University of Sydney established the Australian Vietnam Medical Foundation, known as Hoc Mai (Forever Learning). The Foundation has "bringing collective knowledge and experience of Australian and Vietnamese healthcare workers in an educational partnership" as its principal aim. A priority of Hoc Mai is to train young potential health leaders from Vietnam in order to strengthen the capacity of individuals and hospitals. Initial funding was from private donations, but over the last two years, with the support of the Australian Government program AusAID, Hoc Mai has expanded significantly with 20-35 Vietnamese doctors, nurses, pharmacists and technicians having been sponsored to go to Australia each year.

In addition, over 150 Australian medical students have had short clinical attachments in Vietnam. Many Sydney Medical School (SMS) clinical academics have also visited Vietnam as individuals to share their knowledge and expertise.

\footnotetext{
${ }^{1}$ Sydney Medical School, The University of Sydney, NSW, Australia

${ }^{2}$ Hanoi Medical University, Hanoi, Vietnam

Corresponding Author: Dr. O. F. Dent,

Sydney Medical School, The University of Sydney, NSW, Australia

As a result, strong ties and personal friendships have developed. In recent years, teams of clinical academics from SMS have visited Vietnam regularly to teach clinical skills and medical English to Vietnamese clinicians and academics.

Our Vietnamese colleagues believe that it is essential that the next generation of Vietnamese doctors be comfortable with medical English as a way of expanding their clinical horizons and improving the health of the Vietnamese population. English is regarded as essential for accessing medical literature via the internet, for overseas postgraduate study, for international conference attendance and for publishing research in international journals.

In December 2009 a one-day workshop was held at Hanoi Medical University (HMU) at which the Rector of HMU, senior academics, clinicians and educators met with SMS staff to discuss educational priorities at HMU. The four goals which the HMU leadership decided to be the most important in a learning program for young Vietnamese clinicians and medical teachers were: (a) to further develop competence in medical English, (b) to develop skills in defining undergraduate course learning objectives, (c) to introduce new teaching techniques and (d) to introduce new methods of student assessment. 
With these four goals in mind, Hoc Mai developed an Advanced Course in Medical Teaching which was conducted over 9 months for a small group of highly talented recent HMU medical graduates. The aim was to deliver a part-time course taught in English which would expand their medical horizons, increase their clinical skills and help modernize teaching within the HMU curriculum, particularly in specifying learning objectives and developing clinical assessments. The course was prepared in consultation with senior academics at HMU.

It was envisaged that the young doctors who completed this advanced course would be well-equipped to become academic leaders in Vietnam, and be able to pass on the skills they have learned to their peers as well as to the undergraduates they will be teaching (Fan et al., 2012). They would become agents for change (Burdick et al., 2007). We expected that the participation in this advanced course would also increase their chance of winning overseas postgraduate scholarships.

\section{The Course at Hanoi Medical University}

Funding for the first instalment of the course in 2010-2011 was generously provided by the Atlantic Philanthropies. Initially, 50 outstanding recent medical graduates were nominated by the Rector of HMU. They were then interviewed by SMS representatives to select the 30 best applicants in terms of their ability to comprehend and speak English. Those chosen were young doctors from a broad range of disciplines including adult internal medicine, paediatrics, obstetrics and gynaecology, surgery, radiology, pathology, biochemistry and microbiology.

The course comprised six one-week blocks distributed over the period from September 2010 to May 2011 with each block consisting of four three-hour evening sessions. Lecturers were SMS clinical academics from a broad range of medical specialties and their teaching emphasized general educational principles broadly applicable across disciplines rather than their own particular areas of expertise. The topics covered are listed in Table 1.

Table 1: Topics covered in the Advanced Medical Teaching Course at Hanoi Medical University (2010-2011)

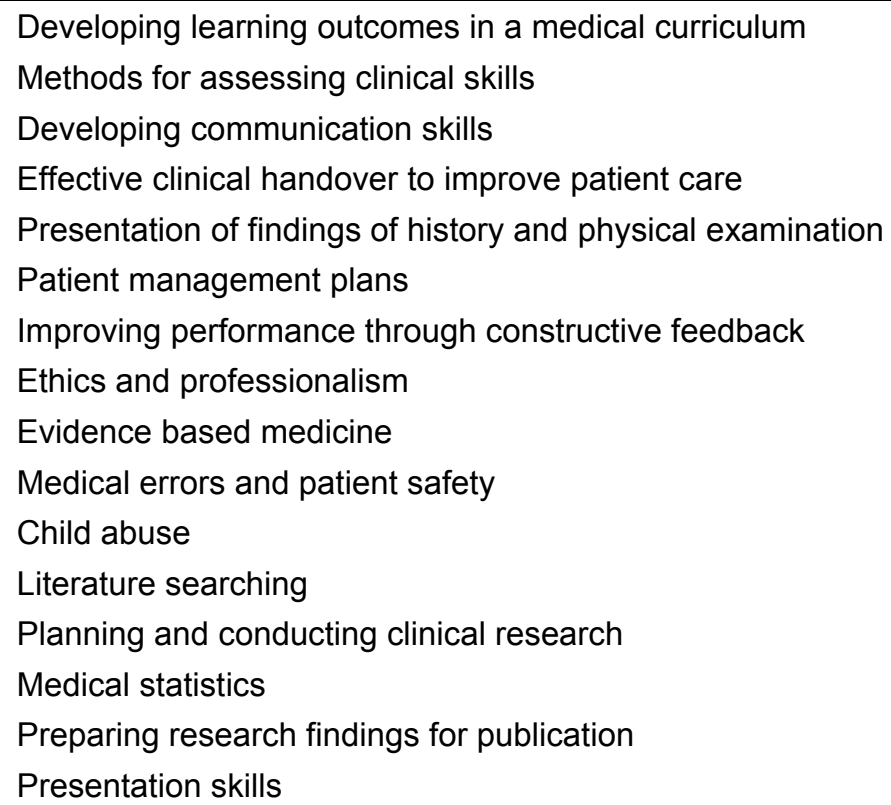

Teaching methods included short interactive lectures, informal question and discussion sessions, tasks for participants to work on in small groups, role-playing of patient scenarios and computer-based bibliographic activities and statistical exercises. Opportunities for feedback, both positive and negative, were provided throughout the course (Blatt et al., 2009). Academic clinicians from HMU were invited to co-teach with the Australian academics in each block of the course, enhancing the skills and involvement of these established Vietnamese teachers. 


\section{Participant satisfaction}

Five of the course blocks were evaluated separately and anonymously by the participants with a standard set of questions. A large majority of the participants thought that the lectures were easy or very easy to understand $(90 \%)$ and thought that the threehour sessions were either about the right length or too short (91\%). Ninety-seven percent found the topics either very interesting or fairly interesting and $86 \%$ felt they could understand all or most of the course content. All thought that their clinical work would change to some extent as a result of the course. Not all of these doctors were involved in teaching, but $97 \%$ of those who were, thought that the course was highly or fairly relevant. They thought that their teaching would change to some extent as a result of the course.

The final block in the program was on research methods, statistics and publishing research. All participants who were engaged in research or teaching research procedures felt that this block was either highly relevant or fairly relevant to them and that their research and teaching would change as a result.

Participants who attended regularly had about 60 hours of attendance, in addition to time spent in preparation and follow-up. When asked whether they thought the course was worthwhile, considering the time they had devoted, $99 \%$ said that it was either mostly or very worthwhile. Ninety-two percent said that they would recommend the course to others.

A final evaluation of the entire course was subsequently conducted by an independent agency and yielded a strong positive overall assessment.

\section{Test-retest assessment of learning}

At the beginning of each block, participants answered 6 to 12 multiple choice questions on their knowledge of the topics to be covered during the block. The same questions were repeated at the end of the block. The overall score at the end of every block was greater than at the beginning, indicating that most participants had benefited from th e course.

\section{The Course at Sydney Medical School in 2011}

In addition to the HMU component of the course, eleven participants were selected by HMU to travel to Sydney for a two-week intensive course in July, 2011. The topics included in this course are shown in Table 2. An evaluation of the formal sessions showed that participants thought that the lecturers spoke at the right speed and were easy to understand; most sessions were neither too long nor too short; the topics were either fairly interesting or very interesting; most or all of the content was understandable; projected slides and hand-outs were helpful; and the lectures were relevant to and would influence their clinical work, teaching and research.

Table 2: Topics covered in the Advance Medical Teaching Course held conducted at the Sydney Medical School in July 2011

How to give stimulating and memorable lectures

Dilemmas in medical ethics

Assessment of students at Sydney Medical School

Practical aspects of medical education

Medical English

Activities at the Sydney Clinical Skills and Simulation Centre

Radiology and the future of computing in clinical medicine

What journal editors look for

Giving effective feedback

Issues concerning children in research

Teaching medicine and surgery to young doctors

Evidence-based medicine

Clinical research for a busy clinician

Planning individual cooperative research projects 
During the second week in Sydney, the 11 young graduates from HMU were each paired with a clinical research mentor in their area of interest from the Sydney Medical School. Their task was to prepare and conduct, over the subsequent 12 months, a clinical research project which will be conducted in a hospital allied with HMU by the Vietnamese clinician with ongoing input from the SMS clinical researcher. The aims were to concentrate on achievable projects which would improve clinical care in Vietnam, to be transferable to other Vietnamese hospitals, to present at international conferences and publish in international medical journals, co-authored by the HMU and the SMS clinician/researchers.

\section{Expected outcomes of the course}

In the long term, graduates of this course will have:

- Enhanced clinical and teaching skills which will make them better clinicians and teachers and will improve the care of those they treat.

- Increased likelihood of being accepted for postgraduate studies outside Vietnam and of obtaining scholarships.

- Increased opportunities for combined Vietnam-Australian research projects and joint publications.

- Improved competence in spoken and written English

- Experience and skills that will enable them to play a major role as future leaders in Vietnamese medicine.
The course was repeated with some minor changes in 2012 and is currently in progress in 2013.

\section{Acknowledgements}

The clinical academics from SMS who visited HMU in 2011 were - Kerry Goulston, Wendy Hu, David Isaacs, Siriam Mahadev, Charlie McDonald, Ian McPhee, Craig Mellis, Chris Needs, Kim Oates and Owen Dent

Teachers in the intensive course at SMS in July 2011 were - Rob Baxter, Leo Davies, Chris Dennis, Owen Dent, Kirsty Foster, Bruno Guiffe, Tom Hugh, David Isaacs, Lyn March, Charlie McDonald, Craig Mellis, Kim Oates, Margaret Schnitzler, Geoff Tofler, Leonie Watterson, and Phillip Yuile.

\section{References}

Blatt, B., Kallenberg, G., Lang, F., Mahoney, P., Patterson, J.E., Dugan, B. \& Shaobang, S. (2009) Found in translation: exporting patientcentered communication and small group teaching skills in China [online], Medical Education Online, 14, available at http://www.med-ed-online.org.

Burdick, W.P., Morahan, P.S. \& Norcini, J.J. (2007) Capacity building in medical education and health outcomes in developing countries: the missing link [online], Education for Health, 65, available at $h t t p: / / w w w . e d u c a t i o n f o r h e a l t h . n e t$.

Fan, A.P., Tran, D.T., Kosik R.O., Mandell, G.A., Hsu, H.S. \& Chen, Y.S. (2012) Medical Education in Vietnam, Medical Teacher, 34, pp. 103-107. 